\title{
Mitteilungen der Redaktion
}

Die Herausgeber und Herausgeberinnen bedanken sich ganz herzlich für die konstruktive Mitarbeit der GutachterInnen im Jahr 2012. Die Gutachten trugen wesentlich zur inhaltlichen und formalen Qualitätsentwicklung und -konsolidierung der Beiträge und damit auch des Journals bei.

Als GutachterInnen waren tätig:

Ulrich Bartosch

Roland Becker-Lenz

Mechthild Bereswill

Doris Bühler-Niederberger

Matthias Grundmann

Peter Hermann

Ulrike Loch

Heinz-Günther Micheel

Ingrid Miethe

Peter Pantucek

Mark Schrödter

Mike Seckinger

Uwe Sielter

Cornelia Wustmann 